\title{
Desarrollo Social de la Ciudad-Región
}

\section{Social Development of a Regional City}

\author{
Germán Rozas O.*
}

\section{Resumen}

La vida en la ciudad requiere madera, minerales, agua, alimentos. Estos elementos son extraídos principalmente de regiones lejanas. El resultado es un impacto en la vida de las comunidades regionales, las cuales presionadas por sus condiciones de vida son forzadas a migrar. La población migrante no es bien recibida por la ciudad, deben instalarse en los márgenes de la misma. Esta nueva situación da inicio a la configuración de un proceso de conflicto social. Por un lado surge la delincuencia y por otro la exacerbación de políticas policiales. Esta es nuestra civilización: una ciudad dividida y enfrentada. Al respecto se plantea desde la Psicología Comunitaria algunas orientaciones que busca el interculturalismo, la valoración de la diversidad y particularmente la necesidad de un proceso de sostenibilidad social.

Palabras Claves: Calidad de vida; Espacios regionales, Interculturalismo.

\section{Abstract}

Life in the city requires wood, minerals, water, and food. These needed elements are generally obtained from distant places. The result is an imapct on the life of said regional communities, which are pressured by their living conditions, and are therefore forced to migrate. Inmigrant populations are not welcomed in the city, and therefore settle in the outskirts thereof. This new situation creates a process of social conflict. On one side, delinquency arises, and on the other, the exacerbation of police policies. This is our civilization: A divided and antagonized city. To that respect, the viewpoint that is planted by Community Psychology is to orient towards interculturalism, the valuing of diversity, and the need for a sustainable social harmony.

Key Words: Quality of Life; Region; Interculturalism.

\footnotetext{
* Psicólogo, Magister Universidad de Bruselas, Bélgica. Departamento de Psicología, Universidad de Chile. e-mail: grozas@uchile.cl
} 


\section{El Crecimiento de la Ciudad, en Cuestión}

La ciudad ha tenido un proceso permanente de crecimiento. Hacia el año 1860 la Ciudad de Santiago de Chile tenía aproximadamente 100.000 habitantes, sin embargo 100 años después, en 1960 su tamaño había aumentado 21 veces al llegar a 2.100.000 habitantes.

Entre 1940 y 1970 el Gran Santiago aumento su población a una tasa superior al $3 \%$ anual, llegando en la década de los años 50 en que creció a una tasa más allá del $4 \%$ anual. Posteriormente la tasa anual de crecimiento se redujo al 2,6\% entre 1970 y 1982 luego a un $1,7 \%$ entre 1982 y 1992. ( Bolivar, 1994).

No obstante el año 1982 llego a una población de 4 millones, en 1992 a 4,7 millones y según la más reciente estadística, Santiago tiene actualmente en 1998 tiene 6 millones de habitantes.

En 1970 la población en Chile llegaba a 8 millones 800 mil habitantes. Aproximadamente la mitad, 4 millones 600 mil vivían en ciudades de 50.000 habitantes, el resto 4 millones 200 mil vivían en pueblos pequeños, en el sector rural. En 1952 había 7 ciudades de 50 mil habitantes y más, en 1960 ya existían 13 ciudades, en 1970 ya eran 16 ciudades de 50 mil y más habitantes (Bolivar 1994).

Los datos anteriores apuntan fundamentalmente a señalar la importancia del crecimiento en cuanto al número de habitantes de las ciudades en Chile, particularmente la ciudad capital, Santiago. Sin embargo este crecimiento va acompañado también de una extensión territorial.

El crecimiento físico de la ciudad de Santiago se ha realizado a través de una expansión horizontal semejante a lo que se ha denominado un " mancha de aceite» (CED 1990). Entre 1900 y 1940 pasa de contar con
4 mil hectáreas a ocupar casi 11 mil (CED, 1990). Luego su expansión llegaba a 38,2 hectáreas en 1982, pasando posteriormente a tener 45 mil hectáreas en 1987 (Serplac, 1990).

En este sentido la ciudad de Santiago ha cuadruplicado su territorio en los 50 últimos años (1940-1990). De modo que el cruzar la ciudad de un punto a otro puede tomar de dos a tres horas.

Esta situación es relativamente generalizada en los países de América Latina. Es destacable el caso de ciudades como Sao Paulo, Ciudad de México, Buenos aires, Río de Janeiro, Lima, que se encuentra entre las 25 ciudades más grandes del mundo. (Rozas, 1998)

Es complejo plantearse respecto de las bondades que tiene esta situación de crecimiento urbano. Aquí se encuentran en juego muchos valores, intereses y diferentes enfoques de vida .

Para algunos la ciudad es sinónimo de desarrollo, es un símbolo de la vida moderna. Permite el acceso a los beneficios del progreso. Es también el triunfo de la ciencia, representa el éxito del hombre sobre el control de las cosas. En este sentido la ciudad es un espacio construido satisfaciendo los sueños del hombre desafiando a la misma naturaleza. Es la liberación de las ataduras que depara el mundo animal y natural.

Para otros la ciudad representa la mala comprensión que tiene el hombre de su relación con la naturaleza. En su afán de liberarse a construido su propia cárcel. Por cuanto el progreso no ha traído un beneficio sino lo contrario, contaminación, artificialidad, pobreza, congestión, delincuencia, inseguridad, mala calidad de vida, estrés, enfermedades mentales, etc. Se plantea que el progreso de la ciudad es un concepto mal entendido, que ha producido una desnaturalización del hombre. 
El crecimiento de la ciudad no sólo es referente al número de habitantes, sino también en su expansión territorial aparece un mayor consumo de electricidad, de agua, de materias primas, de áridos para la construcción, de minerales para la industria. La mayor cantidad de habitantes implica también volúmenes mayores de alimentos, de vestuario, de artefactos del hogar, automóviles.

Se quiere llamar la atención en este artículo que el crecimiento territorial de la ciudad la gran mayoría de las veces se hace a expensas de otras zonas regionales, muchas veces dedicadas al cultivo agrícola, con presencia de bosque nativo, con fuentes naturales de agua. Ello en base a que la rentabilidad de la producción es inferior al valor del suelo en función de la construcción de vivienda $u$ otro tipo de infraestructura.

Es apreciable también que el crecimiento de la ciudad en latinoamérica es de un modo espontáneo e irregular. El cual sin planificación ocupa espacios inapropiados para las funciones que se les asigna, se levanta infraestructura que al corto andar se constituye en verdaderos obstáculos a un flujo más expedito de sus habitantes, como así mismo se levantan barreras y murallas que generan división social, provocando delincuencia, violencia y enfrentamiento social.

\section{La Ciudad, Complice en el Deterioro de la Región}

En el contexto territorial de una región la ciudad no se ubica en la misma categoría con relación a otros espacios regionales. Podríamos decir que son como dos cuerpos apartes que desarrollan un tipo de relación desigual. La ciudad se constituye en el centro y el resto del territorio en espacios marginales. La energía y el esfuerzo de la sociedad está orientada a privilegiar la ciudad en detrimento del espacio regional.

Dicho de otra forma, lo que importa es el desarrollo de la ciudad, el resto del espacio territorial es secundario y se encuentra al servicio de la ciudad. Su función fundamental no es velar por su propio desarrollo sino en satisfacer los caprichos de la ciudad. No es relevante el desgaste, el deterioro que puede sufrir un espacio regional, lo significativo es cumplir con las necesidades de la ciudad aunque ello implique su degradación. La ciudad aparece como una especie de niña mimada.

En esta relación se privilegia el desarrollo de la ciudad y se posterga el desarrollo de la región.

Por otro lado la ciudad se proyecta fundamentalmente como consumidora y los otros espacios regionales se configuran esencialmente como proveedores. El conjunto de recursos presentes en la región deben destinarse a satisfacer las necesidades de la ciudad. Si ciertos recursos regionales se terminan de consumir , no importa, se recurrirá a otros espacios regionales. La ciudad así descrita se configura es una suerte de parásito en relación al entorno regional. La ciudad vive a expensas de la región.

Al decir de Borja y Castells (1997), «La concentración de población en las urbes y su desarrollo se ha realizado en los últimos años a partir de la explotación de recursos naturales cada vez más alejados, sin que se hayan establecido las medidas oportunas para posibilitar la recuperación de éstos ni se disponga de las funciones de regeneración y salvaguarda de los espacios naturales que tradicionalmente suponía la vida en las zonas rurales. Todo ello ha significado un sobreexplotación de este tipo de recursos y un aumento significativo a nivel de residuos...» (pág. 196). 
El crecimiento de las ciudades desarrolla principalmente el sector secundario y terciario. El sector primario se encuentra fuera de las ciudades, en el entorno o en otros espacios regionales, e incluso otras regiones son las destinadas a ejercer el rol de producción de materias primas.

La función de la región es proveer materia prima para las necesidades de la industria ubicada en la ciudad y para los servicios que requiere la población de las ciudades. La materia prima es el insumo para el crecimiento urbano. Se busca la calidad de vida de la ciudad, sin importar el deterioro y el desgaste y disminución de la calidad de vida de la región.

Al respecto Borja y Castell (1997) señalan lo siguiente «Las ciudades del mundo sufren un grave problema de sostenibilidad local y global derivado de las formas de organización urbana, la inadecuada gestión y unas pautas de consumo incontroladas e inconscientes especialmente en las áreas de mayor riqueza, que llevan al despilfarro de recursos. La presión ejercida sobre el medio urbano y sobre el ecosistema global por los procesos de urbanización es cada vez mayor. Esto conduce a una pérdida de capital natural, sin que haya políticas adecuadas de control, mejora del capital existente y renovación o sustitución de lo consumido» (pág 196).

Uno de los ejemplos paradigmáticos al respecto es el caso del Agua:

Una de las necesidades fundamentales de la ciudad hace referencia a este vital elemento. El Agua recurso básico de la vida humana a pasado a ser un tema estratégico de alto valor. Disponer de agua en el mundo actual define a un espacio como rico o como pobre. El problema para la ciudad es que requiere de grandes volúmenes para el consumo de la población, y para el consumo de las industrias elaboradoras de materias primas.
En primer término se extrae agua de la misma ciudad, sin embargo cuando las napas subterráneas son agotadas la ciudad se ve obligada a canalizar el vital elemento desde otras regiones. Si dichas regiones son agotadas se recurre a otras. Sin embargo esta explotación creciente, pasado cierto límite comienza a impedir la utilización del agua para beneficio de los espacios regionales donde se extrae, y ello a mediano plazo conduce a generar pobreza en dichos lugares.

Clásico es el caso de consumo distante de agua en Ciudad de México. A medida que evolucionó el siglo pasado ciudad de México se fue expandiendo. La necesidad de agua , hizo necesario perforar pozos de captación de agua en su mismo territorio. Sin embargo estos pozos deprimieron la napa subterránea y provocaron hundimientos de tierra....En 1958 se realizó la primera transferencia de agua desde el Valle del Lerma con el fin de satisfacer la demanda creciente. Esta transferencia causó alteraciones ecológicas en dicho Valle, deprimió también sus napas subterráneas secó sus lagunas. Además, creo serios problemas políticos y sociales a sus habitantes, (CEPAL, 1991.)

En 1950 Ciudad de México tenía cinco millones de habitantes, y en 1984 tres veces más. Como consecuencia de ese crecimiento, la demanda de agua creció exponencialmente. Se ha debido transferir aguas desde la cuenca del río Cutzamalá y todavía no es suficiente. Se calcula que en este nuevo siglo se tendrá que traer aguas desde fuentes a más de 200 klms.

Al nivel más general, pero involucrando el crecimiento de la ciudad se encuentra el aumento de consumo del agua según necesidades de la industria, en función de consumo interno o la exportación de sus productos. Es el caso dramático del Mar Aral.

El Mar Aral, en la Ex Unión Soviética, fue un Lago de extraordinaria belleza, con- 
siderado el cuarto más grande del mundo. En cuatro décadas se transformó en un especie de desierto salado. Al inicio de la producción de algodón se utilizaron terrenos y cursos de aguas de Asia central, ubicación del lago. Se construyeron grandes canales de irrigación de cientos de kilómetros de largo aprovechando las aguas de dos ríos tributarios del mar Aral. A los pocos años se empezó a superar a China y a EE.UU. en la exportación de algodón, (Lilian Duery, 1999)

Sin embargo en la década del 60 el lago empezó a reducir su tamaño. A la fecha ha perdido un $80 \%$ de su volumen, dejando a su retiro 3,6 millones de hectáreas que eran fondo del lago. La pobreza a llegado a las poblaciones que rodean el lago. Por el colapso de la pesquería y otras actividades que dependían de este inmenso curso de agua, más de 100 mil personas tuvieron que emigrar hacia otros lugares para sobrevivir. La población que queda sufre un fuerte impacto directo, la agricultura apenas se mantiene y son víctimas de tormentas constituidas por polvos tóxicos del fondo salado del lago.

Otro proceso de las necesidades fundamentales de la ciudad es la producción agrícola, también para su consumo interno y exportación del país. La dinámica agrícola constituye un largo proceso de explotación del campo de larga data, sujeto a múltiples variables sociales, políticas, culturales. Atendiendo específicamente el uso del suelo agrícola asistimos históricamente a un gran proceso de degradación de la tierra. La riqueza de la tierra no es la misma de antes. Sus recursos han diminuido significativamente. Han aumentado de modo relevante los procesos de desertificación.

Originalmente la tierra, sujeta a un proceso natural de evolución, se encontraba poblada particularmente por árboles, árboles nativos. La sociedades indígenas implementaron zonas agrícolas pero relati- vamente menores y básicamente orientadas a la autosubsistencia. Sin embargo la aparición del mundo occidental alineado tras la idea del progreso trajo consigo un concepto de maximización productiva al uso de la tierra.

De esta forma y de modo sistemático, planificado y otras veces de manera irregular y espontánea, se comenzó un proceso de deforestación, talando miles de hectáreas de árboles y destinando la tierra a la agricultura y a la crianza de animales.

La agricultura intensiva y especialmente el monocultivo, genera condiciones de no biodiversidad, lo que lleva la tierra a un proceso de desgaste, de perdida de nutrientes y minerales, de modo que el suelo raso ahora, desprovisto de árboles y plantas se enfrenta sin protección a la erosión producto del paso del aire y de las lluvias. Generando posteriormente tierras de mala calidad y desiertos. Esta pérdida en muchos lugares es irreversible.

En cierta medida esto está ocurriendo en Chiapas, según González L. (1993) «El gran problema de deforestación se observa especialmente en Chiapas, donde se destruye aceleradamente el patrimonio natural. En la década de 1970 se estimaba que tres cuartas partes (74\% del territorio Chiapaneco) estaban constituidas por superficies forestales, $y$ a principios de los ochenta se calculaba que éstas formaban menos de la mitad de la superficie del Estado (47\%). La principal causa del proceso de deforestación en el estado es el acelerado proceso de ganaderización, que avanza fundamentalmente a costa de las superficies selváticas» (pág 137). Está demás decir la pobreza que ello ha significado en la zona y consecuentemente el conflicto social que hoy vive México.

Estos procesos y otros explican como la ciudad ejerce una presión económica sobre los recursos naturales. Sin embargo dicha 
presión no es inocente, está fuertemente relacionada con el estilo de vida que ha desarrollado la sociedad. La forma de vida, el consumo, los patrones de conducta ambiental de los habitantes de la ciudad han generado una sobredemanda de los recursos naturales y con ello ha provocado el deterioro y degradación en los espacios regionales.

Al decir de Leff E. (1993) «La sequía y la desertificación no son catástrofes naturales sino procesos causados por los modos de producción y patrones tecnológicos de explotación de recursos» (pág. 36).

Es importante señalar que esto es una cadena donde la degradación ambiental y la sobreexplotación de recursos parte primariamente desde los países desarrollados, que luego involucra a los países subdesarrollados quienes hacen gala de patrones imitativos de consumo, siguiendo en todas las situaciones una exigencia desde las ciudades hacia el ámbito rural.

Al respecto según los antecedentes de la FNUAP «Se ha establecido que los habitantes de los países desarrollados que representan el 25\% de la población Mundial, utilizan el $75 \%$ de toda la energía producida, consumen $79 \%$ de todos los combustibles comerciales, y $85 \%$ de todos los productos de madera... producen casi $75 \%$ de todas las emisiones de bióxido de carbono... más un porcentaje igualmente desproporcionado de otros gases que causan el efecto invernadero, ( Leff E., 1993, pág. 36).

En el caso chileno el quintil más rico de la población consume cerca de siete veces más agua que el quintil más pobre, ( Escudero y Lerda, 1997).

Se concluye esta sección con Leff E. (1997), que señala «La degradación ambiental se debe más a patrones de consumo de las sociedades opulentas con bajas tasas de natalidad que al crecimiento demográfico de los pueblos del tercer y cuarto mundo...
Tampoco es el número creciente de pobladores rurales el que produce, por ese sólo hecho, los procesos de deforestación, sino los patrones de uso de suelo de una agricultura altamente capitalizada, orientada hacia el mercado mundial y los paquetes tecnológicos inapropiados para los ecosistemas (...) , lo que ha venido ocasionando la destrucción de sus prácticas de manejo sustentable de recursos, originando procesos forzados de migración y de inestabilidad que expulsan a la población hacia zonas cada vez más frágiles y los lleva a adoptar estrategias de sobrevivencia», (pág. 36).

\section{Perdida de Sustentabilidad Social a Nivel Regional}

El agotamiento de los recursos como la tierra y el agua, y otros, sin dejar fuera la contaminación, contribuye notoriamente a disminuir las posibilidades de vida de las poblaciones que habitan esos espacios regionales. Esto pasa especialmente con las comunidades rurales, las más apartadas, las comunidades indígenas, el sector campesino.

La población local, radicada en los espacios regionales comienza a sufrir un notorio proceso de deterioro social. La comunidad comienza a desestructurarse, se pierde su propia identificación cultural, pierde legitimidad la autoridad de los adultos y los antiguos, los jóvenes empiezan a emigrar, la comunidad pierde su principal recurso que es la juventud.

Este proceso es muy complejo, hay muchas variables comprometidas como son las agroindustria, la tecnificación del trabajo agrícola, las construcción de represas, la degradación del suelo, la forestación no nativa, el monocultivo, etc. La pobreza causa la migración. La población migra a la ciudad, de alguna forma obligada por falta 
de trabajo y por deficientes condiciones de desarrollo. Los migrantes ven en la ciudad, el lugar de solución de todos los problemas.

De esta manera se genera un círculo vicioso perverso. El campo pierde recursos fundamentales para la sobrevivencia, por lo tanto necesaria migración de la población local a la ciudad, luego crecimiento del número de habitantes en el espacio urbano, lo que implica necesariamente aumento del consumo de agua, luz, y otros recursos, finalmente esto a la vuelta repercute en mayor explotación de recursos naturales de los espacios regionales, de la zona rural.

Un caso en este sentido es la Central Pangue. En el sector del Alto Bío Bío, en la VIII Región de Chile, denominado Angostura de Pangue, se está construyendo la central Hidroeléctrica Panque (Ralco). La construcción de la represa de 113 metros de alto por 450 metros de largo dará origen a un embalse de 175 millones de metros cúbicos de capacidad, inundará 500 hectáreas de tierra y bosque nativo. La potencias de generación eléctrica será de 450 megawatts. Este proyecto pretende satisfacer la creciente demanda de electricidad que se calcula en un crecimiento de un $5,5 \%$ a un $6 \%$ ( Saar Van Hauwermeiren, 1994).

Pero, el Alto Bío Bío también es el hogar del pueblo Pehuenche, una de las ramas de los Mapuches. Se estima que en la zona comprendida entre el río Bío Bío y la Laguna Icalma habitan unos diez mil Pehuenches. La instalación de la central significa una amenaza para esta cultura. Se ha subrayado que la asalarización de los Pehuenches que trabajen en la construcción de las centrales significará un procesos irreversible de abandono de las actividades tradicionales de subsistencia y de transformación de sus hábitos laborales y costumbres sociales. A larga cuando se produzca el término de faenas y su consecuente despido, los pehuenches tendrán dificultades para readaptarse a sus actividades tradicionales y probablemente muchos de ellos migrarán a las ciudades a buscar nuevos trabajos asalariados. Ello será un fuerte estímulo para la lenta desintegración de las comunidades indígenas del Alto del Bío Bío.

El caso de las comunidades indígenas como así mismo comunidades campesinas en relación a distintos tipos de producción, como por ejemplo las forestales, es que la degradación de la tierra ya sea por un cultivo intensivo como por la erosión o la desertificación produce la reducción de los recursos disponibles para dichas comunidades. Ello es particularmente alarmante por cuanto dichas comunidades viven del campo, y de sus recursos. No disponen de otras alternativas, al mismo tiempo las técnicas de producción que manejan están asociadas a dichos recursos bajo ciertas condiciones. La falta y deterioro de esas condiciones trae inmediatamente como consecuencia el empobrecimiento de las comunidades y con ello un conjunto de procesos de deterioro social.

Emigran los jóvenes en busca de trabajo hacia la ciudad, desconfían de sus padres que no tienen elementos que satisfagan sus necesidades como jóvenes, lo que al poco andar implica una perdida de la cultura, de sus mecanismos y estrategias de producción y de vida.

Otro ejemplo interesante es el caso de la contaminación del Valle del Huasco ubicado en le III Región de Atacama, Chile. En el Valle del Río Huasco la agricultura ha sido tradicionalmente la actividad más importante dadas sus características hídricas, geográficas y climáticas. Se dan condiciones favorables para el cultivo de cereales, hortalizas, forestales y frutales, como olivos, parronales e higueras. Por otra parte, en el sector costero existe una gran cantidad de caletas, dada la abundancia de peces, mariscos y recursos 
marinos, entre los que se destacan el congrio colorado, la merluza y el jurel, las machas, ostiones y jaibas (Saar Van Hauwermeiren, 1994).

La Compañía Minera del Pacífico S.A. eligió el Valle de Huasco para instalar su planta pelletizadora de hierro (Pellet: material granulado producido por la fundición de minerales, para ser usado como materia prima). En 1977 puso en marcha sus faenas de triturado y molienda emitiendo desde entonces por sus chimeneas una 40 toneladas diarias de material particulado y gran cantidad de gases quimicotoxicológicos. Además evacúa y descarga al mar, en la ensenada de Chapaco, 172 toneladas por hora de relaves y residuos industriales.

Las actividades de la CMP han contaminado la atmóstfera del lugar provocando graves daños en la salud de los habitantes, así como también en la vegetación y en los cultivos agrícolas, especialmente en los olivares. La descarga al mar de relaves ha afectado el sustrato rocoso del litoral e impedido el proceso de fotosíntesis indispensable para la vida de la flora y fauna marina. Asimismo la sedimentación de sólidos decantables ha provocado la reducción del plancton que es arrastrado al fondo y asfixiado.

En el caso de los Olivos el impacto se reflejó claramente en los rendimientos. La producción de aceitunas en el Huasco hacia fines de la década de los setenta era de unos diez millones de kilos. En 1991 la producción ha bajado a menos del diez por ciento.

Las emanaciones también tienen efectos en las personas. Considerando la cantidad y composición química de los gases y las partículas de metales pesados respirables y acumulables en el organismo, se puede imaginar el impacto en la salud de los habitantes al respirar durante 20 años estas emanaciones. El plomo es considerado como un ele- mento altamente tóxico, tiene efectos adversos en el Sistema Nervioso Central de los organismos en desarrollo. Las mujeres en edad reproductiva, las mujeres embarazadas, los bebés y los niños tienen mayor riesgo. Las enfermedades recurrentes que presentan los habitantes de Huasco son cataratas, callosidades en la córnea, cáncer, asma y enfermedades al aparato respiratorio en general. Entre los niños se observa un elevado número con epilepsia.

Por otra parte, los pescadores y buzos de la Bahía Chapaco, acusan a la empresa de contaminar el medio marino. Desde su instalación la empresa ha producido el embancamiento de la bahía, el deterioro del fondo del mar de forma irreversible, por lo tanto se ha destruido la flora y prácticamente se ha terminado con la fauna marina.

Más dramática aún ha sido la situación vivida por las comunidades indígenas de la región «El oriente» en el Ecuador. Estas comunidades han puesto una demanda (en los EE.UU.) contra la empresa petrolera Texaco por los abusos cometidos contra el medio ambiente y la población de la zona. La región involucra trece millones de hectáreas de selva tropical, en los alrededores del río amazonas, donde cohabitan 95 mil indígenas pertenecientes a ocho etnias diferentes y alrededor de 250 mil inmigrantes que llegaron junto a las petroleras en los años 70. (Chocano de la Rosa, 1999)

Se estima que la empresa Texaco inyectaba al medio ambiente alrededor de 10 millones de galones de agua contaminada, es decir cerca de 250 mil barriles de desperdicios tóxicos en la selva amazónica. El agua, que contenía crudo, sales y metales duros, comenzó a decantar lentamente en los ríos y zonas húmedas de la región durante 20 años.

Las poblaciones aledañas han comenzado a presentar enfermedades a la piel, además un alto número de abortos espontá- 
neos y también casos de cáncer. La selva ha sido deforestada, la contaminación de las aguas perjudica los cultivos, los peces mueren, interrupción en la cadena de reproducción de las especies de la región.

Esto ha significado la miseria de los habitantes de la región. Por cuanto la destrucción de su medio ambiente ha terminado con su sistema económico, basado en la pesca, caza y recolección.

\section{Saturación de la Ciudad, Baja Calidad de Vida y Desencuentro Social}

Como se observa en el punto anterior, la realidad en los espacios regionales, rurales se ven afectados en sus condiciones de vida por las crecientes demandas de la ciudad. Se provoca una disminución de las condiciones de vida, pobreza, falta de recursos productivos, degradación del medio ambiente. El conjunto de estos deterioros implica una constante migración, son los jóvenes quienes emigran, buscando nuevas alternativas laborales, dejando atrás sus familias, su cultura, sus padres y parientes.

Más del $70 \%$ de la población Latinoamericana vive en Ciudades. La ciudad es un polo de atracción, se espera encontrar en ella la solución a todos los problemas. Hoy día ya no son las luces de la ciudad lo que convoca sino la necesidad de trabajo. Es el acicate de las malas condiciones de vida en el campo (Rozas, 1980).

Sin embargo fatalmente la migración no es bienvenida en la ciudad, no es esperada. No existen condiciones de infraestructura , de salud, de educación, de vivienda, etc. que permitan su integración social. El crecimiento de la ciudad en relación a sus fuentes productivas, requieren una alta calificación lo que genera malas condiciones de recepción para nueva población demandan- te. De una u otra forma los migrantes son un contingente de trabajadores que sobra.

Las dificultades que depara la ciudad, trabajos complejos, problemas de idioma, alta calificación, uso corriente de la lectura y escritura, estímulos al consumo, nuevos valores y nuevos estándares, ofrece un contexto de modernización cultural frente al cual el migrante no está preparado. El fracaso es relevante y paralelo en muchas dimensiones, su cultura autóctona muchas veces no cuenta con las matrices y recursos de adaptación a esta nueva realidad y por lo mismo empieza a ser abandonada, surge entonces un proceso de aculturación.

En este contexto los migrantes se acomodan a la vida de la ciudad. Ello significa restringir su calidad de vida al mínimo para subsistir y esperar la oportunidad de trabajo. Las oportunidades no existen o se traducen en trabajo muy menores, muy mal remunerados, en altas condiciones de riesgo e inseguridad.

Su asentamiento no tiene otra alternativa que producirse en espacios marginales de la ciudad. Esto es radicarse en territorios degradados, de riesgo o de muy mala calidad de vida . Espacios cercanos a las industrias y empresas, a orillas de la línea del tren o de flujos viales, en viviendas colindantes con espacio de deshechos de la ciudad, próximo a vertederos de basura y residuos tóxicos.

Un ejemplo en este sentido es el asentamiento de familias pobres en el entorno de industrias peligrosas. En Santiago de Chile en el límite de la Comuna de San Bernardo y la Comuna de lo Espejo existe un parque industrial con industrias peligrosas. En 1997 se produjo un incendio en la Industria Química Mathiesen Molypac. Concurrió el cuerpo de bomberos y el despliegue de su acción sólo aumento el incendio por reacción de diferentes químicos. El incendio disminuyó gradualmente, pero tuvo una duración de 
dos meses. Murió una persona, cuidadora del colegio cercano, si el incendio hubiese sido en día de semana probablemente las víctimas habrían sido mayores, especialmente niños. La nube tóxica mantuvo a la población con serios problemas respiratorios, hay antecedentes de a lo menos 6 personas con indicadores de cáncer producto de la alteración del aire.

La pobreza urbana, en la cual se subscribe la migración, presenta un patrón de concentración espacial que tiende a coincidir con las zonas de mayor vulnerabilidad ambiental o de riesgo frente a catástrofes de la Naturaleza. Un ejemplo en este sentido es lo ocurrido en Buenos Aires, Argentina.

Las zonas bajas de los barrios de Belgrano, Núñez, Palermo, Villa Crespo, las zonas aledañas a Riachuelo y bajo Flores y las urbanizaciones de Lugano se han constituido en verdaderas trampas. En efecto entre el 31 de mayo y el $1^{\circ}$ de Junio de 1985 cayeron sobre Buenos aires, Argentina, 308 milímetros de agua. Ello provocó una inundación que hizo necesario evacuar a 100 mil personas, dañó 2.500 viviendas y 14.000 vehículos motorizados, y dejó sin luz eléctrica, teléfono ni agua corriente a 100 mil viviendas. Hubo un saldo trágico de víctimas. (CEPAL, 1991). Estos ejemplos plantean la relación entre pobreza y zonas de mayor vulnerabilidad ambiental.

Por otro lado, en la evolución del fenómeno migratorio se produce el traslado de otros miembros de la familia de origen, igualmente hay reproducción en la familia migrante. De esta manera aumenta el volumen de población la cual, como se señalaba, no tiene un soporte estructural para su desarrollo en la ciudad. Este proceso genera el nacimiento de nuevas poblaciones en la ciudad constituidas en términos de barrios marginales, barrios pobres con muy mala dotación de infraestructura y servicios, ge- neralmente distantes de los centros de actividad, alejados de las fuentes laborales.

La pobreza, la cesantía, el escaso poder adquisitivo, problemas de índole social son entre otros los factores que explican la delincuencia. Fundamentalmente el delincuente es producto de condiciones de vida deterioradas.

La delincuencia tiene un proceso de evolución al cual no nos vamos a referir, no obstante, se ejerce de forma principal en aquellos sectores que disponen de recursos, en los barrios acomodados, barrios que no son marginales.

$Y$ aquí comienza a aparecer otro elemento de la secuencia que se quiere indicar, el desencuentro cultural.

En un estudio realizado en la comuna de Conchalí (Trivelli, 1997), perteneciente a la Ciudad de Santiago, se observan zonas respecto percepción de seguridad. En el sector percibido con mayor inseguridad, coincidente con mayores porcentajes de delincuencia, existe un comportamiento acorde de la población del entorno de evitar dichos espacios y de tomar medidas de seguridad, altas rejas, murallas, cierres, alarmas.

Esta situación parcial proyectada a nivel de la ciudad permite observar un fenómeno similar. La ciudad de Santiago pareciera dividida en dos grandes segmentos uno de población acomodada y otro de población pobre y necesitada. La Delincuencia se dirige desde el segundo al primer sector. Por lo mismo las autoridades Comunales del sector más acomodado toman constantemente medidas de vigilancia, lo que implica contratación de guardias, vehículos, sistemas organizados de control y de monitoreo, etc.

Han aumentado significativamente los Condominios. La empresas inmobiliarias construyen un conjunto de viviendas ro- 
deadas por murallas, donde en su interior existen toda clase de comodidades sin importar lo que ocurra afuera y luego este circuito está fuertemente custodiados con diferentes sistemas de alarmas, guardias, perros amaestrados, rejas, entrada controlada, etc.

La ciudad está segmentada y separada, existe una suerte de batalla de agresión informal y formal entre unos y otros. Se ha producido una escalada de mecanismos de control y de sistemas de vigilancia y de represión. Todo lo contrario de lo que se pudiera esperar de una ciudad moderna y civilizada.

Vivimos la era de la ciudad, pero al mismo tiempo es la época del gran desencuentro social, de la separación, del rechazo a la relación entre diferentes grupos sociales. $\mathrm{Al}$ mismo tiempo vivimos inmersos en el miedo, en la inseguridad, con temor a la agresión y a la violencia. Sin embargo tenemos temor a un otro, igual a uno en tanto individuo y ser humano. El otro es estigmatizado, como una especie de monstruo y se le asigna un lugar lo más alejado posible y "protegido», que lo mantenga allí retenido.

Los otros, son rechazados, son marginados, se les ponen barreras y murallas, se les impide su acceso, no se les dan facilidades, y mas bien se les ubica en barrios alejados, que se constituyen en especies de reservas sociales, de una u otra forma cercadas a través de distintos mecanismos visibles e invisibles. El objeto es proteger otros barrios, especialmente aquellos más acomodados y con mayores recursos.

\section{Desencuentro Social}

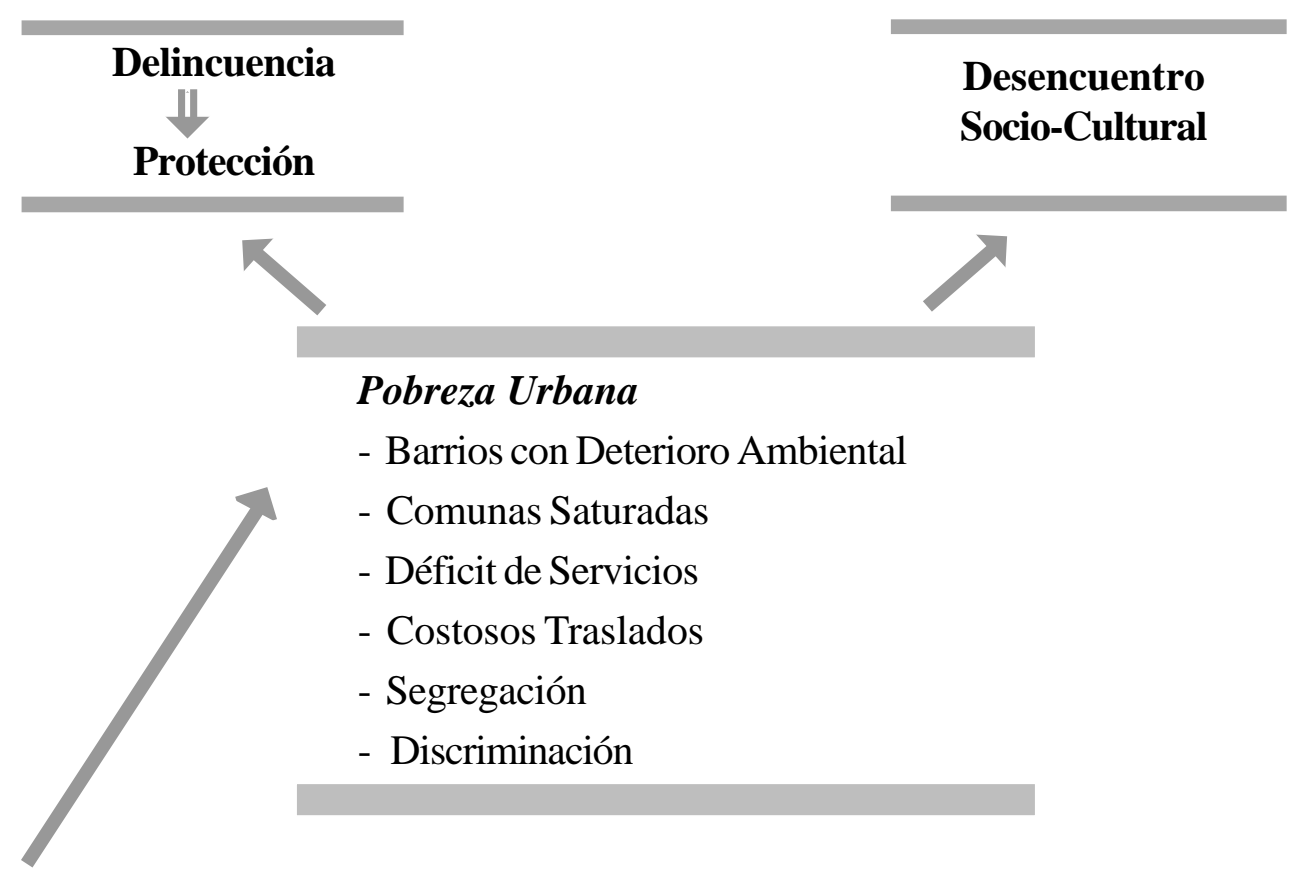

Migración a la Ciudad

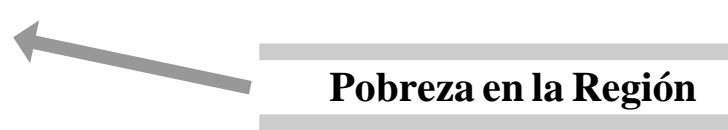


En este plano el crecimiento de la ciudad debiera hacer suyo el concepto de sustentabilidad social, el que entre otras cosas debiera dirigir un esfuerzo a producir un acercamiento entre las personas, entre diferentes grupos sociales, entre diferentes culturas, entre indígenas y no indígenas. La sustentabilidad social en el ámbito urbano es el esfuerzo hacia un encuentro social que permita conocer, valorar y reconocer el aporte cultural y productivo de los otros y el propio. .

Una espacio urbano civilizado debiera tener sistemas de acogida a distintos grupos y culturas de modo que permita un mejor tránsito y mejor adaptación de migrantes y de nuevas culturas a la ciudad.

\section{Propuesta Desde la Psicología Social Comunitaria}

Esto hace necesario generar una mirada distinta, no centrada en la ciudad sino en la región o territorio. En la región también se encuentra población que tiene derecho a una adecuada calidad de vida, sin embargo existe pobreza y condiciones de vida que dejan mucho que desear.

El planteamiento central de la presentación es que frente a la meta del desarrollo es importante tener un punto de partida regional. La región incluye una ciudad o varias, sectores rurales, territorios mineros, pesqueros, $\mathrm{u}$ otros. Es decir, la región es un mosaico de diferentes elementos a contemplar.

Antaño e igualmente hoy día, el desarrollo ha sido un carro tirado por las ciudades, transformándose en polos de desarrollo. Se ha incentivado y valorado su crecimiento. Sin embargo ha llegado el momento que nos detengamos y miremos este proceso desde otra perspectiva, desde la altura que nos permite una mirada regional.
Este enfoque abre ante nuestro análisis distintas realidades presentes en la región, las cuales en interacción unas con otras permiten observar las líneas de influencia y dependencia. No obstante también permite valorizar diferentes culturas locales, capacidades y riquezas sociales diversas.

En el análisis y diagnóstico regional aparecen diferentes poblaciones humanas encaminadas hacia un tipo de progreso local definido culturalmente, que en su despliegue da cuenta de los recursos humanos, habilidades y potencialidades propias. Surge una mirada territorial como un bien altamente valorado, por cuanto se encuentra asociado a la vida y a los esfuerzos de sobrevivencia de un grupo humano.

Por ello el asumir una perspectiva regional genera las condiciones que permite valorizar y poner todos los actores y recursos en un mismo nivel sin privilegiar unos por sobre otros y desde allí promover una articulación horizontal de los actores, valorando las distintas líneas de desarrollo y gestionando un proceso de propuesta regional que abandone la exclusiva atención sobre la ciudad y se vuelque al conjunto de áreas de la región. Avanzando en evitar las dependencias, las jerarquías, la explotación regional a distancia. Ello en un proceso de negociación y acuerdos que permita colectivamente contribuir desde la particular perspectiva local al desarrollo de la región.

La sostenibilidad es también integración social. Las políticas sociales que tienden a la integración de las poblaciones a través de la educación, el empleo, el acceso a la vivienda, el control demográfico y la salud, etc., no pueden separarse de los procesos para conseguir un desarrollo sostenible. La sostenibilidad social obliga a asegurar la inclusión de todos los grupos de población al desarrollo económico. 
Según Borja y Castells (1997) «Hacer Región (ciudad) sólo es posible si se dota de un proyecto de desarrollo económico que combine la competitividad con la sostenibilidad respecto de los recursos no renovables y el medio ambiente y con la cohesión social, es decir el empleo, la vivienda, el acceso a los servicios, la participación cívica y la integración cultural» (pág 186).

Metodológicamente este proceso es factible de llevarlo a cabo desde diferentes modelos. Uno de ellos es el de Gestión Territorial, otro desde el enfoque OEA, también desde la Planificación Situacional, etc. Todos ellos tiene en su interior aspectos como participación, negociación, diagnóstico, procesos de acción, evaluación, desarrollo de actores, etc. El punto tal vez no es cual modelo, sino el poner énfasis en la perspectiva regional y particularmente la valorización de actores locales habitualmente marginados del desarrollo.

Por otro lado ya estamos en un mundo globalizado, sin embargo como ha quedado demostrado por los recientes conflictos a nivel mundial como el caso de Kosovo, de Palestina, de Chiapas, de Bosnia o en el caso de Chile con los Mapuches, se esta haciendo evidente el desarrollo de un perfíl de identidad local y la necesidad de responder a las urgencias locales.

La modernidad implicó de alguna forma una vinculación con el centralismo, lo que a su vez produjo una fuerte tendencia a la homogeneización. La globalización en ese sentido aloja una fuerza a conformar las regiones y los individuos en seres similares. Sin embargo esta uniformidad constituye en su esencia una exclusión aberrante de la realidad humana en sus particularidades.

Al decir de Boisier S. (1996) «Si en algún momento la ilusión de la modernidad albergó la idea de que era posible crear al ciudadano del mundo, libre de 'atávicos' lazos te- rritoriales, hay que convenir que la crisis de la racionalidad moderna echó por tierra tal creencia. Hoy día por el contrario se percibe un movimiento de vuelta al terruño»....»La aparición o reaparición de las sociedades locales es una reacción popular, que nace en la base, ante el desarraigo engendrado por la modernidad occidental; es una cierta necesidad de 'calor humano' y de convivialidad reencontrada, es un mecanismo de microidentificación que busca contrarrestar la macroanonimización, es la búsqueda de espacios de libertad al abrigo de un juego institucional del cual se sabe excluido, y una reacción de rechazo a formas tradicionales de lucha hoy inocuas» (pág. 22-23).

$Y$ continua señalando «En efecto, las así llamadas ideas post modernas, enfatizan y valorizan la diversidad, la heterogeneidad y la fragmentación y con ello reivindican la unicidad e identidad del territorio original y menor (la vuelta a lo local)» ( Boisier S, pág 6 , 1993).

En el mundo globalizado la región garantiza la sustentabilidad, por cuanto permite un equilibrio entre la ciudad y los espacios regionales. Y ello se condice con la perspectivas de hoy día, en donde no sólo está en juego la dimensión económica sino también el Capital Social, es decir la capacidad de organización, la presencia de un conjunto de redes eficientemente articuladas, la cohesión social.

El desarrollo de la identidad local y regional, como parte fundamental del capital social, permite la conformación de una orientación común de la región. El crecimiento requiere un denominador común dentro de la misma, un conjunto de elementos compartidos por los distintos actores de la región. Ello permitirá enfrentar de mejor modo los procesos de competencia y desarticulación a nivel nacional y mundial.. Lo contrario una región o una comunidad fragmentada, des- 
unida, se enfrentará con menos fuerza a las redes globales del poder y de la riqueza.

La región debe dejar de fomentar la división, la explotación, la usurpación de materias primas por parte de la ciudad. Por el contrario, la generación de espacios de encuentro, de líneas de comunicación, de espacios de educación y de adquisición de nuevas experiencias, de valorización y consideración prácticas de otras formas de resolver los problemas. Todo ello hará que la región sea percibida al interior y al exterior como poseedora de un proyecto aglutinador. La población desarrollará un vínculo de pertenencia con su hábitat, un vinculo de protección y defensa del mismo, de modo de que incorporará formas sostenibles de producción.

Una región en condiciones de desorden, de autoexplotación, de autodegradación medio-ambiental, no contribuirá a lograr los estándares integrados de crecimiento. Se propondrá al mundo una imagen de región ineficiente, polucionada, autodestructiva.

Ello nos proyecta a estimular el desarrollo de recursos estratégicos desde la Psicología Comunitaria, desde la Psicología Social, en función del crecimiento regional. Algunas líneas de las cuales pueden ir en la orientación de desarrollar un Diagnóstico territorial, a través de una intervención participativa en un contexto de generación de redes sociales y procesos de negociación.

Los estudios de carácter regional generalmente no consideran los aspectos culturales, psicosociales, de identidad, cosmovisiones, de gran relevancia en la generación de un proyecto aglutinador conjunto. Consideran escasamente, a veces como dato estadístico los recursos sociales, mujeres, niños, jóvenes, trabajadores, quienes más bien son vistos desde su proyección demográfica.

Al respecto quisiera terminar este artículo citando a Enrique Leff (1997)quién enfatiza la importancia de la Psicología Social y en el campo del desarrollo regional propone líneas de investigación como: " ...percepción de los recursos, la conciencia del ambiente, los valores culturales asociados al acceso y uso de los recursos y las prácticas tradicionales de uso de los recursos, sobre la innovación tecnológica incorporada a las normas culturales y las restricciones y potenciales ecológicos de cada región, sobre las motivaciones de expulsión y migración , o para el arraigo y la renovación de identidades culturales, sobre el fortalecimiento de las economías autogestionarias, fundadas en el potencial de sus recursos ambientales y en su integración al mercado mundial. .....Podría diagnosticar los niveles de vida en función del grado de satisfacción de las necesidades básicas de la población y de sus aspiraciones culturalmente definidas....dicho nivel inducirá factores para normar y regular el comportamiento reproductivo de la población por un conjunto de valores ( asociados a la familia pequeña, la calidad de la maternidad y la paternidad), y con la autoregulación proveniente de los mismos procesos de gestión ambiental» (Pág 45).

\section{Bibliografía}

BOISIER S. (1996), «Modernidad y Territorio», Cuadernos № 42, Ed. ILPES, Stgo., Chile.

BOISIER S. (1993), Postmodernismo territorial y globalización: regiones pivotales y regiones virtuales. Documento 93/19 Ed. ILPES Stgo., Chile.

Bolivar A., Coulumb R. y Muñoz C., (1993) "Metrópoli, Globalidad y Modernización" Ed. Flacso y Universidad Autónoma Metropolitana Azcapotzalco, Ciudad de México, México. 
BoRJa J. y CASTELLS M. (1997), «Local y Global», Ed.Santillana, Taurus, Madrid, España.

CED (1990) «Santiago, dos ciudades», Ed. Centro de Estudios del Desarrollo, Santiago, Chile.

CEPAL (1991), "El Desarrollo Sustentable", Santiago de Chile.

Chocano de la Rosa I. (1999), «Las Aguas de la Ira», Diario El Mercurio, 3 Abril de 1999.

DUERY L.(1999) «Un desarrollo No Sustentable: Mar Aral, hoy un desierto salado por mal uso del agua», Diario El Mercurio 20 de Mayo de 1999

Escudero J. y SANDRA L. (1997) "Implicaciones ambientales de los cambios en los patrones de consumo en Chile» en Sunkel O., Sustentabilidad ambiental del crecimiento económico Chileno, Ed. Programa de Desarrollo Sustentable, Centro de Análisis de Políticas Públicas, Universidad de Chile.

GonZÁLEZ, L.(1993) «Distribución de Población, Ambiente y Análisis Regional» en: Yzazola y Lerner, Población y Medio Ambiente, Ed. Sociedad Mexicana de Demografía, México D.F.

Guevara J, Landázuri A.M. y Terán A. (1998) "Estudios de Psicología Ambiental en América Latina", Ed. Universidad Autónoma de Puebla, Facultad de Psicología, Maestría en Psicología Social, Puebla, México.
LEFF E. (1993), “La interdisciplinariedad en las relaciones Población-Ambiente. Hacia un paradigma de demografía Ambiental» en Yzazola y Lerner, Población y Medio Ambiente, Ed. Sociedad Mexicana de Demografía, México, D.F.

ROMERO, Rivera y IHL (1997),» $L a$ sustentabilidad Ambiental y el desarrollo Regional», en Sunkel O., Sustentabilidad ambiental del crecimiento económico chileno, Ed. Programa de Desarrollo Sustentable, Centro de Análisis de Políticas Públicas, Universidad de Chile.

RozAs, G (1998), "Psicología Comunitaria, Ciudad y Calidad de Vida», Revista de Psicología, Universidad de Chile Vol VII, pág 6880, Santiago, Chile

SaAr Van Hauwermeiren, (1994) «Consecuencias del crecimiento económicos sobre el medio ambiente: Casos Ilustrativos» en Rayén Quiroga El Tigre sin Selva, Ed. Instituto Ecología Política., Stgo, Chile.

Secretaría Regional de Planificación (Serplac), (1991), "Estrategias de Desarrollo Regional". Mimeo, Santiago de Chile.

TRIBELli, M.S. (1997), «Estudio Exploratorio y Descriptivo de la Sensación de seguridad/Inseguridad Ciudadana y Adopción de Conductas de Prevención al delito asociadas a la Percepción de los espacios del Medio Físico Construido que presentan Individuos de la Comuna de Conchali» Memoria de Grado, Dpto. de Psicología, Universidad de Chile. 